\title{
Enoximone echocardiography: a novel test to evaluate left ventricular contractile reserve in patients with heart failure on chronic beta-blocker therapy
}

\author{
Stefano Ghio ${ }^{* 1}$, Cristina Constantin ${ }^{1}$, Claudia Raineri ${ }^{1}$, Alessandra Fontana ${ }^{1}$, \\ Catherine Klersy ${ }^{2}$, Carlo Campana ${ }^{1}$ and Luigi Tavazzi ${ }^{1}$
}

Address: ${ }^{1}$ Division of Cardiology, Istituto di Ricovero e Cura a carattere Scientifico Policlinico San Matteo, Pavia, Italy and ${ }^{2}$ Division of Biometry and Clinical Epidemiology, Istituto di Ricovero e Cura a carattere Scientifico Policlinico San Matteo, Pavia, Italy

Email: Stefano Ghio* - s.ghio@smatteo.pv.it; Cristina Constantin - cristina.constantin@fastwebnet.it; Claudia Raineri - c.raineri@smatteo.pv.it; Alessandra Fontana - ale.nit@libero.it; Catherine Klersy - c.klersy@smatteo.pv.it; Carlo Campana - c.campana@smatteo.pv.it; Luigi Tavazzi - l.tavazzi@smatteo.pv.it

* Corresponding author

Published: 25 September 2003

Cardiovascular Ultrasound 2003, I:13
Received: 16 April 2003

Accepted: 25 September 2003

This article is available from: http://www.cardiovascularultrasound.com/content/l/I//3

(C) 2003 Ghio et al; licensee BioMed Central Ltd. This is an Open Access article: verbatim copying and redistribution of this article are permitted in all media for any purpose, provided this notice is preserved along with the article's original URL.

\begin{abstract}
Background: It has been suggested that an extensive contractile reserve identified recognised by means of dobutamine stress echocardiography may predict a better prognosis in patients with severe left ventricular dysfunction at rest. However, the clinical use of dobutamine stress echocardiography may be limited in patients with chronic heart failure by the substantial proportion of such patients treated with beta-blockers, since the inotropic response to adrenergic stimulation is known to be attenuated in patients receiving beta-adrenoceptor blockers. Enoximone is a positive inotropic agent that inhibits cyclic adenosine monophosphate-specific phosphosdiesterase. We therefore tested the hypothesis that enoximone may be an alternative to dobutamine in evaluating left ventricular contractile reserve in patients with systolic dysfunction on chronic betablocker therapy.
\end{abstract}

Methods: We studied 26 patients ( 21 males and five females) with a mean age of $58 \pm 10$ years: II were not receiving beta-blockers (noBB group); 15 were receiving carvedilol at a mean dose of $34 \mathrm{mg} /$ day (BB group). Dobutamine was infused at doses of 5 and 10 micrograms $/ \mathrm{kg} / \mathrm{min}$, and enoximone at a dose of $1.5 \mathrm{mg} / \mathrm{kg}$.

Results: The ejection fraction in the noBB group increased by $9 \%$ with dobutamine and $8.73 \%$ with enoximone $(p=0.86)$; in the BB group, it increased by $6 \%$ with dobutamine and $8.94 \%$ with enoximone $(p=0.03)$. Regional peak systolic velocities were evaluated by means of tissue Doppler imaging in four basal and four medium level segments. In the noBB group, they increased more with dobutamine than with enoximone in three of the eight segments; no significant differences were found in the BB group. Dobutamine induced non-sustained ventricular tachycardia in three patients and supraventricular tachycardia in one, whereas enoximone did not induce any repetitive arrhythmias.

Conclusions: Enoximone might be preferable to low-dose dobutamine for evaluating left ventricular contractile reserve in chronically beta-blocked heart failure patients as it is slightly more potent and has a better safety profile. 


\section{Background}

The human myocardium is a predominantly beta-adrenergic organ in which receptor density and sensitivity determine the response to adrenergic stimulation. In patients with severe left ventricular systolic dysfunction, the responsiveness of the beta-adrenergic receptor is diminished as a result of the decreased density of beta- 1 receptors and the decreased sensitivity of beta- 2 receptors [1]. Rapidly growing published data suggest that the presence of a an extensive contractile reserve recognised by means of dobutamine stress echocardiography may predict a better prognosis in patients with severe left ventricular dysfunction at rest. However, the clinical use of dobutamine stress echocardiography in patients with chronic heart failure may be limited by the substantial proportion receiving beta-blocker therapy since the inotropic response to adrenergic stimulation is known to be attenuated in patients receiving beta-adrenoceptor blockers.

Experimental and clinical studies have shown that enoximone has a positive inotropic effect that is not accompanied by a significant increase in myocardial oxygen consumption. It increases coronary blood flow and reduces vascular resistances. The inotropic effect of both enoximone and dobutamine is obtained via the same final biochemical pathway (an increase in intracellular cyclic adenosine monophospate) but by means of different mechanisms: enoximone acts distally to the betaadrenoceptor, and binds directly and selectively to the intracellular enzyme phosphodiesterase III that specifically degrades cardiac cyclic adenosine monophosphate. Its effectiveness is therefore not impaired by beta-adrenoceptor down-regulation or the administration of betablocking agents [2]. A number of studies have previously demonstrated the feasibility and safety of enoximone stimulation in evaluating myocardial viability in patients with ischemic heart disease $[3,4]$, and so the aim of this prospective study was to compare the feasibility of enoximone and conventional low-dose dobutamine echocardiography in assessing myocardial contractile reserve in chronic heart failure patients. We also evaluated regional myocardial function as recent studies have suggested that tissue Doppler is more accurate in identifying myocardial ischemia or viability than conventional stress echocardiography [5-7].

\section{Methods}

\section{Study population}

We selected patients with chronic heart failure due to advanced systolic dysfunction who were referred to our department for heart failure management or heart transplant screening. The inclusion criteria were an ejection fraction of $\leq 35 \%$, sinus rhythm and a clinically stable condition during the previous three months. The exclusion criteria were myocardial infarction or unstable angina in
$\%$

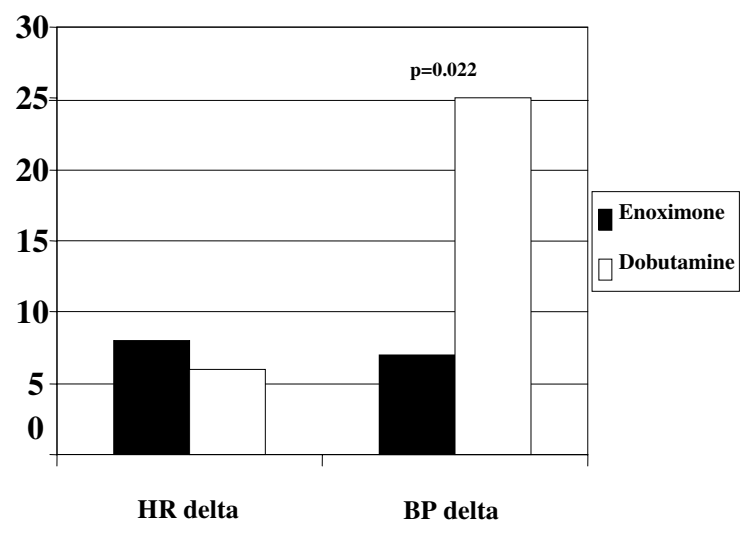

Figure I

Changes in blood pressure (BP delta) and in heart rate (HR delta) in beta-blocked patients, during enoximone and dobutamine stress test.

the previous six months, significant valvular disease, and sustained or non-sustained ventricular tachycardia on recent electrocardiographic Holter monitoring.

We enrolled 26 patients ( 21 male and five females) with a mean age of $58 \pm 10$ years; two patients were in New York Heart Association functional class I, 20 in class II and four in class III. The etiology of heart failure was idiopathic in 13 patients, ischemic in six, hypertensive in three, and unknown in four. Eleven patients were not receiving betablockers (noBB group); the remaining 15 were receiving carvedilol at a mean dose of $34 \mathrm{mg} /$ day (BB group). The baseline characteristics of the patients were similar in the two groups (Table 1).

\section{Study protocol}

Each patient underwent dobutamine and enoximone stress echocardiography on two consecutive days; the test sequence was random. All of the patients gave their written informed consent. Dobutamine echocardiography was performed using a low-dose protocol with incremental doses of 5 and $10 \mu \mathrm{g} / \mathrm{kg} / \mathrm{min}$ at 10 -minute intervals; the images were taken at baseline and at the end of each infusion step. Enoximone echocardiography was performed using a dose of $1.5 \mathrm{mg} / \mathrm{kg}$, which was chosen on the basis of the results of a previous study showing that it had $87 \%$ sensitivity for predicting functional recovery after revascularisation [4]. The enoximone was diluted with saline to a concentration of $2.35 \mathrm{mg} / \mathrm{mL}$ in order to avoid a peripheral venous burning sensation, and infused over ten minutes. The echocardiographic images were recorded at baseline and two minutes after the infusion. 
Table I: Baseline characteristics of the two groups of patients

\begin{tabular}{llll}
\hline & noBB Group & BB Group & P value \\
\hline BP $(\mathrm{mmHg})$ & $114 \pm 16$ & $116 \pm 12$ & 0.76 \\
HR (beats/min) & $72 \pm 8$ & $70 \pm 10$ & 0.45 \\
EDV $(\mathrm{ml})$ & $257 \pm 88$ & $296 \pm 87$ & 0.28 \\
ESV $(\mathrm{ml})$ & $174 \pm 73$ & $219 \pm 82$ & 0.16 \\
EF $(\%)$ & $33.3 \pm 6$ & $27.7 \pm 7$ & 0.04 \\
bsv $(\mathrm{cm} / \mathrm{s})$ & $3.18 \pm 1.79$ & $4.12 \pm 1.51$ & 0.17 \\
$\mathrm{msv}(\mathrm{cm} / \mathrm{s})$ & $2.25 \pm 2.08$ & $4.08 \pm 2.01$ & 0.03 \\
blv $(\mathrm{cm} / \mathrm{s})$ & $3.64 \pm 1.58$ & $2.96 \pm 1.87$ & 0.33 \\
$\mathrm{mlv}(\mathrm{cm} / \mathrm{s})$ & $2.92 \pm 1.88$ & $2.35 \pm 1.43$ & 0.41 \\
$\operatorname{biv}(\mathrm{cm} / \mathrm{s})$ & $3.77 \pm 1.85$ & $3.55 \pm 1.45$ & 0.75 \\
$\mathrm{miv}(\mathrm{cm} / \mathrm{s})$ & $3.34 \pm 2.58$ & $3.10 \pm 3.59$ & 0.78 \\
$\operatorname{bav}(\mathrm{cm} / \mathrm{s})$ & $3.74 \pm 1.62$ & $3.74 \pm 2.41$ & 1.00 \\
$\mathrm{mav}(\mathrm{cm} / \mathrm{s})$ & $2.76 \pm 1.74$ & $2.41 \pm 2.39$ & 0.66 \\
\hline
\end{tabular}

$\mathrm{BP}=$ blood pressure; $\mathrm{HR}=$ heart rate; $\mathrm{EDV}=$ end-diastolic volume; $\mathrm{ESV}=$ end-systolic volume; $\mathrm{EF}=$ left ventricular ejection fraction.; bsv = basal septum velocity; $\mathrm{msv}=$ medium septum velocity; blv = basal lateral velocity, $\mathrm{mlv}=$ medium lateral velocity, biv $=$ basal inferior velocity, $\mathrm{miv}=$ medium inferior velocity, bav $=$ basal anterior velocity, mav $=$ medium anterior velocity.

Table 2: Changes in heart rate and blood pressure in the two groups

\begin{tabular}{llll}
\hline noBB Group & & & \\
\hline & Dobutamine & Enoximone & P \\
\hline$\Delta B P(\mathrm{mmHg})$ & $20 \pm 18$ & $-7.5 \pm 12$ & 0.0025 \\
$\Delta \mathrm{HR}$ (beats/min) & $21 \pm 16$ & $12 \pm 8$ & 0.1742 \\
\hline BB Group & & & $\mathbf{P}$ \\
\hline & & 0.0222 \\
$\Delta \mathrm{BP}(\mathrm{mmHg})$ & Dobutamine & $7 \pm 13$ & 0.5402 \\
$\Delta \mathrm{HR}($ beats/min) & $25 \pm 24$ & $8 \pm 9$ & \\
\hline
\end{tabular}

Abbreviations as in Table I.

During the dobutamine and enoximone studies, a threelead electrocardiogram was monitored continuously and recorded before and after each step of the test. Blood pressure was measured at 5-minute intervals and at the end of the test using a cuff sphygmomanometer. Two-dimensional images were obtained from the apical 4- and 2chamber views and stored on hard disk for the off-line calculation of left ventricular end-diastolic and end-systolic volumes and ejection fraction. Colour tissue Doppler images of the left ventricle in 4- and 2-chamber views were also stored on hard disk for later analysis. All of the studies were performed using a Vingmed System Five ultrasound system. The generated tissue Doppler cineloops were stored on the Vingmed Echopac System hard disk and used for the off-line determination of mean regional systolic velocities. The off-line analyses were made by a physician blinded to the test sequence.

\section{Statistical analysis}

The data are shown as mean values \pm SD for continuous variables, and absolute or relative frequencies for categorical variables. The mean group values were compared using the unpaired t test, and the test results within each group by means of the paired t test. A 2-sided $p$ value of $<0.05$ was considered statistically significant. The computations were made using Stata 7 software (Stata Corp, College Station, TX).

\section{Results}

Blood pressure, heart rate and arrhythmias (Figures I and 2) (Table 2)

Blood pressure increased more with dobutamine than with enoximone in both groups; in the patients not receiving beta-blocker therapy, it actually decreased with enoximone. Symptomatic hypotension occurred in three 
Table 3: Global and regional responses to inotropic stimulation in the noBB Group

\begin{tabular}{llll}
\hline & Dobutamine & Enoximone & P \\
\hline$\Delta$ EDV $(\mathrm{ml})$ & $-23 \pm 20$ & $-18 \pm 25$ & 0.5688 \\
$\Delta \mathrm{ESV}(\mathrm{ml})$ & $-35 \pm 24$ & $-30 \pm 13$ & 0.4791 \\
$\Delta \mathrm{EF}(\mathrm{units})$ & $9.0 \pm 5$ & $8.7 \pm 4$ & 0.8583 \\
$\Delta$ bsv $(\mathrm{cm} / \mathrm{s})$ & $1.75 \pm 2.13$ & $1.26 \pm 1.72$ & 0.6377 \\
$\Delta \mathrm{msv}(\mathrm{cm} / \mathrm{s})$ & $1.11 \pm 2.67$ & $1.54 \pm 1.76$ & 0.6340 \\
$\Delta$ blv $(\mathrm{cm} / \mathrm{s})$ & $2.98 \pm 3.31$ & $1.46 \pm 2.01$ & 0.1780 \\
$\Delta \mathrm{mlv}(\mathrm{cm} / \mathrm{s})$ & $2.48 \pm 1.84$ & $0.97 \pm 2.09$ & 0.0320 \\
$\Delta$ biv $(\mathrm{cm} / \mathrm{s})$ & $2.17 \pm 2.21$ & $0.92 \pm 0.79$ & 0.0561 \\
$\Delta \mathrm{miv}(\mathrm{cm} / \mathrm{s})$ & $1.31 \pm 3.34$ & $0.84 \pm 0.75$ & 0.6420 \\
$\Delta$ bav $(\mathrm{cm} / \mathrm{s})$ & $3.81 \pm 2.53$ & $0.10 \pm 3.17$ & 0.0174 \\
$\Delta \mathrm{mav}(\mathrm{cm} / \mathrm{s})$ & $2.80 \pm 2.53$ & $0.03 \pm 2.17$ & 0.0170 \\
\hline
\end{tabular}

$\Delta=$ difference between stress and baseline values; other abbreviations as in Table I.

Table 4: Global and regional responses to inotropic stimulation in the BB Group

\begin{tabular}{llll}
\hline & Dobutamine & Enoximone & P value \\
\hline$\Delta$ EDV $(\mathrm{ml})$ & $-5 \pm 22$ & $-12 \pm 20$ & 0.1508 \\
$\Delta$ ESV $(\mathrm{ml})$ & $-20 \pm 26$ & $-33 \pm 17$ & 0.0136 \\
$\Delta$ EF $(\mathrm{units})$ & $6 \pm 6$ & $8.9 \pm 6$ & 0.0323 \\
$\Delta$ bsv $(\mathrm{cm} / \mathrm{s})$ & $1.30 \pm 1.17$ & $1.12 \pm 1.44$ & 0.7709 \\
$\Delta \mathrm{msv}(\mathrm{cm} / \mathrm{s})$ & $1.20 \pm 1.24$ & $0.38 \pm 1.2$ & 0.0682 \\
$\Delta$ blv $(\mathrm{cm} / \mathrm{s})$ & $0.09 \pm 4.99$ & $1.50 \pm 1.09$ & 0.3171 \\
$\Delta \mathrm{mlv}(\mathrm{cm} / \mathrm{s})$ & $0.17 \pm 3.28$ & $1.85 \pm 1.65$ & 0.1876 \\
$\Delta$ biv $(\mathrm{cm} / \mathrm{s})$ & $1.81 \pm 2.1$ & $1.07 \pm 1.74$ & 0.1759 \\
$\Delta \mathrm{miv}(\mathrm{cm} / \mathrm{s})$ & $1.56 \pm 1.58$ & $1.15 \pm 1.18$ & 0.3251 \\
$\Delta$ bav $(\mathrm{cm} / \mathrm{s})$ & $0.65 \pm 2.46$ & $1.61 \pm 1.38$ & 0.1954 \\
$\Delta \mathrm{mav}(\mathrm{cm} / \mathrm{s})$ & $0.06 \pm 2.62$ & $1.15 \pm 1.66$ & 0.2862 \\
\hline
\end{tabular}

$\Delta=$ difference between stress and baseline values; other abbreviations as in Table I.

patients; it was mild (peak systolic pressure no less than $90 \mathrm{mmHg}$ ) and rapidly recovered spontaneously (two cases) or after liquid infusion (one case). There was no significant difference in heart rate response between the two agents. Dobutamine induced non-sustained ventricular tachycardia in three patients and supraventricular tachycardia in one, whereas no repetitive arrhythmias were observed during the enoximone test.

\section{Global left ventricular function (Tables 3 and 4)}

Although the inotropic agents decreased end-diastolic volume to a similar extent in both groups, enoximone decreased end-systolic volume significantly more in the patients receiving beta-blocker therapy. Consequently, in the noBB group, the ejection fraction increased by $9 \%$ with dobutamine and $8.73 \%$ with enoximone $(\mathrm{p}=0.86)$ and, in the BB group, it increased by $6 \%$ with dobutamine and $8.94 \%$ with enoximone $(\mathrm{p}=0.03)$.

\section{Regional myocardial function (Tables 3 and 4)}

In the noBB group, tissue velocities increased more with dobutamine than with enoximone in three of the eight segments analysed: the basal and medium anterior segments, and the medium lateral segment. There were no statistically significant differences in regional tissue velocities in the $\mathrm{BB}$ group.

\section{Discussion}

The evaluation of left ventricular contractile reserve seems to be a promising new tool for the prognostic stratification of patients with heart failure. We tested the hypothesis that enoximone may have a better safety profile than dobutamine, and that it may be a better inotropic stimulus for patients on chronic beta-blocker therapy and therefore applicable to a larger proportion of patients with heart failure. The results indicate that enoximone does not induce repetitive arrhythmias and that it is slightly more 


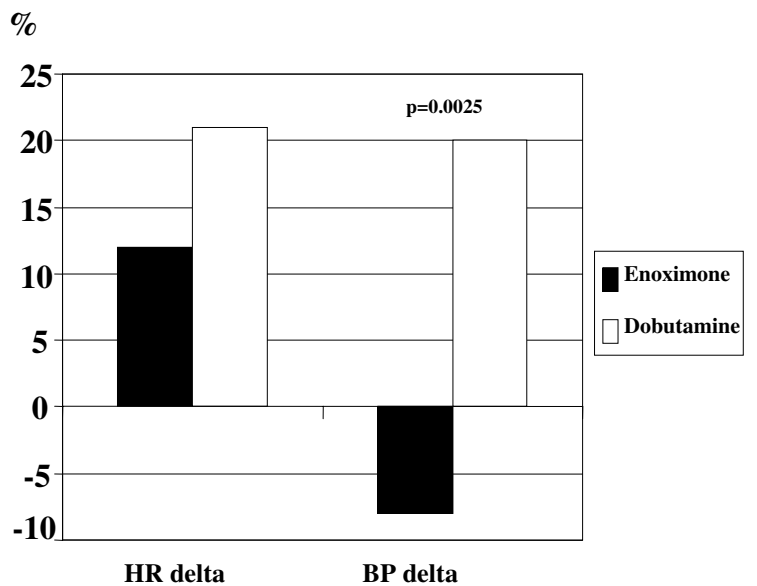

Figure 2

Changes in blood pressure (BP delta) and in heart rate (HR delta) in non beta-blocked patients, during enoximone and dobutamine stress test.

potent than low-dose dobutamine in patients on chronic beta-blocker therapy.

\section{Dobutamine stress echocardiography for evaluating inotropic reserve}

It has been found that an extensive contractile reserve identified by dobutamine stress-echocardiography is associated with better survival [8-11] and predicts recovery of left ventricular function in patients with recent onset idiopathic dilated cardiomyopathy [12-15]. More, in patients with ischemic heart disease and left ventricular dysfunction, the myocardial viability recognised by low-dose dobutamine echocardiography is associated with better survival [16]. However, few of these studies evaluated patients on chronic beta-blocker therapy. The great majority of heart failure patients currently receive chronic betablocker therapy, which is known to interfere with the response to dobutamine: a recently published study has demonstrated that long-term carvedilol therapy inhibits the hemodynamic response to dobutamine, whereas the response to enoximone is not significantly changed [17]. Moreover, the previous studies did not use the same dobutamine stress echocardiography protocol, with some authors using high doses of dobutamine in order to reveal myocardial contractile reserve [10]; however, the use of high dobutamine doses may lead to a high arrhythmic risk in patients with advanced left ventricular dysfunction.

\section{Enoximone stress echocardiography for evaluating myocardial viability}

A number of studies have attempted to identify viable myocardium in patients with ischemic heart disease, and it has been shown that it can be identified after a myocardial infarction as precisely and safely by means of an enoximone bolus as by means of dobutamine infusion; the sensitivity, specificity and overall accuracy of enoximone stress echocardiography in predicting reversible dysfunction after myocardial infarction were respectively 93\%, 85\% and 88\% [3]. Another study used enoximone echocardiography to predict functional recovery after myocardial revascularisation, and found that it was more sensitive and had a greater negative predictive value than dobutamine, and also induced fewer hemodynamic alterations [4]. Finally, enoximone has been combined with very low-dose dobutamine in order to detect myocardial viability in the infarcted myocardium of patients with severe heart failure and life-threatening arrhythmias [18].

\section{Enoximone stress echocardiography for evaluating left ventricular contractile reserve}

In our study, the ejection fraction increased to a similar extent in the patients not receiving beta-blockers after both low-dose dobutamine and enoximone but, in the patients on chronic beta-blocker therapy, it not only increased more with enoximone, but also (and interestingly) to the same extent as in the non-treated patients. These results are consistent with the theoretical background and the results of studies of post-infarction patients $[3,4]$.

We also measured regional myocardial velocities by means of tissue Doppler echocardiography because recent studies have suggested that tissue Doppler data can accurately identify myocardial viability or ischemia [5-7]. However, the information gathered by evaluating regional myocardial velocities in our patients could not replace the assessment of global systolic function. In the noBB group, tissue velocities increased more with dobutamine in three of the eight analysed segments (the basal and medium anterior segments and the medium lateral segment) whereas, in the $\mathrm{BB}$ group, no significant difference was observed in any segment. It is possible that the low baseline tissue velocities due to advanced left ventricular dysfunction, and the less potent inotropic stimulus (which was used to assess the presence of contractile reserve rather than to elicit the occurrence of ischemia), may explain this difference in comparison with previous studies.

In terms of safety, enoximone did not induce any repetitive arrhythmias, which is very important when studying patients with left ventricular dysfunction who are, by definition, at increased arrhythmic risk. The few cases of mild hypotension occurring with enoximone rapidly resolved.

One limitation of the present study is that we only enrolled patients with a NYHA functional class of no 
more than III. We did not study more advanced patients and we cannot predict the potential adverse effects of the two inotropic agents in such subjects. We also cannot predict the safety profile of enoximone in patients with sustained ventricular arrhythmias.

\section{Conclusions}

Enoximone proved to be as useful as low-dose dobutamine in evaluating left ventricular contractile reserve in chronically beta-blocked heart failure patients, but its better safety profile makes it preferable for such a purpose.

\section{Competing interests}

None declared.

\section{Authors Contribution}

SG partecipated in designing the study and drafted the manuscript; CC partecipated in designing the study, carried out the stress tests and partecipated in drafting the manuscript; AF and CR carried out the stress tests, CK performed the statistical analysis; CC and LT partecipated in drafting the manuscript.

\section{References}

I. Fowler MB, Laser JA, Hopkins GL, Minobe W and Bristow MRL: Assessment of the beta-adrenergic receptor pathway in the intact failing human heart: progressive receptor downregulation and subsensitivity to agonist response. Circulation 1986, 74: $1290-1302$

2. Lowes BD, Simon MA, Tsvetkova TO and Bristow MR: Inotropes in the beta-blocker era. Clin Cardiol 2000, 23(Suppl 3):IIII I-6.

3. Natale E, Minardi G, Wang F, Tubaro M, Giovannini E, Vajola SF and Milazzotto F: Identification of viable myocardium early after acute myocardial infarction under beta-blockade by enoximone echocardiography. G Ital Cardiol 1997, 27:342-348.

4. Lu C, Carlino M, Fragrasso G, Maisano F, Margonato A, Cappelletti A and Chierchia S: Enoximone echocardiography for predicting recovery of left ventricular dysfunction after revascularization. A novel test for detecting myocardial viability. Circulation 2000, I01:1255-1260.

5. Fathi R, Cain P, Nakatani S, Yu HCM and Marwick TH: Effect of tissue Doppler on the accuracy of novice and expert interpreters of dobutamine echocardiography. Am J Cardiol 200I, 88:400-405.

6. Rambaldi R, Podermans D, Bax JJ, Boersma E, Elhendy A, Vletter W, Roelandt JR and Valkema R: Doppler tissue velocity sampling improves diagnostic accuracy during dobutamine stress echocardiography for the assessment of viable myocardium in patients with severe left ventricular dysfunction. Eur Heart J 2000, 21:1091-8.

7. Cain P, Baglin T, Case C, Spicer D, Short L and Marwick TH: Application of tissue Doppler to interpretation of dobutamine echocardiography and comparison with quantitative coronary angiography. Am J Cardiol 200I, 87:525-53I.

8. Dubois-Randé LL, Merlet $P$, Roudot F, Benvenuti $C$, Adnot S, Hittinger L, Duval AM, Syrota A, Castaigne A, Loisance D and Geschwind HJ: Beta-adrenergic contractile reserve as a predictor of clinical outcome in patients with idiopathic dilated cardiomyopathy. Am Heart J 1992, I 24:679-85.

9. Scrutinio D, Napoli V, Passantino Ricci AA, Lagioia R and Rizzon P: Low-dose dobutamine responsiveness in idiopathic dilated cardiomyopathy: relation to exercise capacity and clinical outcome. Eur Heart J 2000, 21:927-934.

10. Pratali L, Picano E, Otasevic P, Vigna C, Palinkas A, Cortigiani L, Dodi C, Bojic D, Varga A, Csanady M and Landi P: Prognostic significance of the dobutamine echocardiography test in idiopathic dilated cardiomyopathy. Am J Cardiol 200 I, 88: I374-I378.
II. Paraskevaidis IA, Adamopoulos S and Kremastinos DT: Dobutamine echocardiographic study in patients with nonischemic dilated cardiomyopathy and prognostically borderline values of peak exercise oxygen consumption. J Am Coll Cardiol 2001, 37:1685-9I.

12. Naqvi TZ, Goel RK, Forrester JS and Siegel RJ: Myocardial contractile reserve on dobutamine echocardiography predicts late spontaneous improvement in cardiac function in patients with recent onset idiopathic dilated cardiomyopathy. J Am Coll Cardiol 1999, 34: I537-44.

13. Kitaoka H, Takata J, Yabe T, Hitomi N, Furuno T and Doi YL: Low dose dobutamine stress echocardiography predicts the improvement of left ventricular systolic function in dilated cardiomyopathy. Heart 1999, 81:523-7.

14. Ramahi TM, Longo MD, Cadariu AR, Rohlfs K, Carolan SA, Engle KM, Samady $\mathrm{H}$ and Wackers $\mathrm{FJ}$ Th: Left ventricular inotropic reserve and right ventricular function predicts increase of left ventricular ejection fraction after beta-blocker therapy in nonischemic cardiomyopathy. J Am Coll Cardiol 200I, 37:8I 8-24.

15. Jourdain P, Funck F, Fulla Y, Hagege A, Bellorini M, Guillard N, Loiret J, Thebault $B$ and Desnos : Myocardial contractile reserve under low doses of dobutamine and improvement of left ventricular ejection fraction with treatment by carvedilol. Eur J Heart Fail 2002, 4:269-276.

16. Sicari R, Ripoli A, Borges AC, varga A, Mathias W, Cortigiani L, Bigi R, Heyman J, polimeno S, Silvestri O, Gimenez V and Picano E: The prognostic value of myocardial viability recognized by low dose dobutamine echocardiography in medically treated patients with chronic ischemic left ventricular dysfunction. Circulation 1999, 100(Suppl I):3396 (abstract).

17. Metra M, Nodari S, D'Aloia A, Muneretto C, Robertson AD, Bristow $M R$ and Dei Cas L: Betablocker therapy influences the hemodynamic response to inotropic agents in patients with heart failure. A randomized comparison of dobutamine and enoximone before and after chronic treatment with metoprolol and carvedilo. J Am Coll Cardiol 2002, 40:1248-58.

18. Mangieri E, Alessandri N, Tanzilli G, Barillà F, Puddu EC, Monti F, Canale $G$ and Campa PP: Enoximone coupled to very low dose dobutamine echocardiography detects myocardial viability in akinetic and dyskinetic post-myocardial infarcted areas: Am J Cardiol 1999, 84:264-269.

Publish with Bio Med Central and every scientist can read your work free of charge

"BioMed Central will be the most significant development for disseminating the results of biomedical research in our lifetime. "

Sir Paul Nurse, Cancer Research UK

Your research papers will be:

- available free of charge to the entire biomedical community

- peer reviewed and published immediately upon acceptance

- cited in PubMed and archived on PubMed Central

- yours - you keep the copyright 